Original Research Article

\title{
A study on functional outcome of posterior cruciate ligament substituted total knee arthroplasty
}

\author{
K. Vijaya Bhaskar Reddy, N. Brahma Chary*, Birru Sumanth
}

Department of Orthopaedics, MNR Medical College and Hospital, Sangareddy, Telangana, India

Received: 31 July 2021

Accepted: 18 September 2021

*Correspondence:

Dr. N. Brahma Chary,

E-mail: drnbrahmachary22@gmail.com

Copyright: ( $)$ the author(s), publisher and licensee Medip Academy. This is an open-access article distributed under the terms of the Creative Commons Attribution Non-Commercial License, which permits unrestricted non-commercial use, distribution, and reproduction in any medium, provided the original work is properly cited.

\begin{abstract}
Background: Total knee replacement surgery is considered as a treatment of choice in patients with advanced arthritis, especially in patients where conservative treatment has been failed. Total knee replacement gives good pain relief, functional improvement of knee and correction of deformity.

Methods: This is study of 39 patients following total knee arthroplasty, who were operated between August 2017 and March 2020 at MNR Medical College and Hospital, Sangareddy. They were followed up for a minimum period of 1 year and evaluated using oxford knee scoring system. Oxford knee score is designed specifically for measuring outcomes in knee arthroplasty. There were 14 right knees, 10 left knees, 15 bilateral knees.

Results: There was a significant functional improvement of knee in patients and we had achieved excellent results, out of 39 patients and 4 patients had post op suprapatellar fullness, which was relieved with medications for 3 weeks and 2 patients ( 2 knees) without no signs of immediate post-operative period, developed infection after 6 months followed which underwent staged revision total knee replacement. The outcome categories based on oxford knee scoring system: excellent (40-48), good (30-39), fair (20-29) and poor (0-19).

Conclusions: It is difficult to balance the knee with retention of posterior cruciate ligament, whereas posterior cruciate ligament substituting total knee replacement gives reproducible and good results, hence it is the preferred mode of management.
\end{abstract}

Keywords: Osteoarthritis, Oxford knee score, Posterior cruciate ligament

\section{INTRODUCTION}

In most arthritic knees, some degree of instability, deformity, contracture, or a combination of these elements, can be found. The common causes of arthritis of the knee in adults include Osteoarthritis (OA), Rheumatoid Arthritis (RA), Post-Traumatic Arthritis or Secondary Osteoarthritis and other types of inflammatory arthritis. Osteoarthritis is thought to be the most prevalent chronic joint disorders. The incidence of osteoarthritis is rising because of the ageing population and the epidemic of obesity. Pain and loss of function are the main clinical features that lead to treatment, including conservative and surgical approaches.

Total knee replacement, is a surgical procedure to replace the weight-bearing surfaces of the knee joint to relieve pain and disability. It is most commonly performed for osteoarthritis and also for other knee diseases such as rheumatoid arthritis and psoriatic arthritis. In patients with severe deformity from advanced rheumatoid arthritis, trauma, or long standing osteoarthritis, the surgery may be more complicated and carry higher risk. Most common indication for total knee replacement is osteoarthritis. Various factors are associated with the onset and 
progression of clinical osteoarthritis. These include genetic factors, age, sex, obesity, occupation, abnormal loading of the joint as in kneeling, squatting and cross legged sitting. ${ }^{1,2}$

The concept of improving knee joint function by modifying the articular surfaces has received attention since the 19th century. The surgical techniques have varied from soft tissue interposition arthroplasty to resection arthroplasty to surface replacement arthroplasty. In surface replacement arthroplasty different types of prosthesis were developed to address the complex knee kinematics. Total Knee Arthroplasty (TKA) is now most reliable treatment for severe arthritis. ${ }^{3}$ However, there is a need of a study to accurately assess and analyze the approach of a surgeon towards PCL and measure its outcome. There are some studies in the literature which have specifically compared cruciate- retaining and cruciate substituting designs. ${ }^{4}$ we aimed to study clinical and functional outcome following posterior cruciate ligament substituted total knee arthroplasty.

\section{METHODS}

Study was carried out at MNR Medical college and hospital, Sangareddy, where 39 patients were operated, 54 Total knee replacements done on 39 patients, between August 2017 to March 2020. They were followed up for a minimum period of 1 year and evaluated for clinical outcome using X-rays and Oxford knee score. Patients were followed at 1month, 3 months, 6 months and 1-year, post-surgery. The pre and post-operative pain, deformity and functional outcomes were compared.

\section{Inclusion criteria}

Patients aged 50-70, both male and female with primary both bilateral and unilateral osteoarthritis, traumatic osteoarthritis, genu varus/valgus deformities. Patients walking with the help of walking aids or with the help of assistance before surgery.

\section{Exclusion criteria}

Patients having gross medial and lateral collateral ligament instability, Infective conditions like septic arthritis, Previous history of surgery to knee including arthroscopy, Genu recurvatum, Progressive neuromuscular disorders, Revision TKR, Ankylosed knees, dermatological and infective conditions around knee and Patients with fixed flexion deformity more than 40 degrees.

\section{Pre-operative evaluation}

Detailed history of all patients was taken. All patients were assessed clinically and functionally using the Oxford knee score. The preoperative medical evaluations of all patients were done to evaluate any potential complications that can be life-threatening or limb-threatening. Out of 39 patients, 29 patients had only varus deformity and 10 patients had both varus and fixed flexion deformity less than 40 degrees.

\section{Radiographic assessment}

Standard guidelines were utilized to obtain knee radiographs- standing anteroposterior view, a lateral view, and a skyline view of the patella. Any collateral ligament laxity, subluxation of tibia, presence of osteophytes, any bone defects in the tibia and femur and the quality of bone was assessed. Sizing of the femoral and tibial components was also done.

\section{Operative technique}

All patients after thorough pre-op evaluation, were taken up for surgery under combined epidural and spinal anesthesia, all patients received $1 \mathrm{gm}$ of ceftriaxone $15 \mathrm{~min}$ prior to surgery and tourniquet inflation done. A standard midline medial parapatellar approach was used with knee in 90 degrees flexion. Distal femoral 5-7 degrees of valgus cut is made with help of intramedullary jig and tibial cut is done perpendicular to mechanical axis with the help of extramedullary jig. Femoral and tibial sizing done and appropriate preparation is made. Soft tissue balancing done with trial components in-situ, in both flexion and extension. All patients underwent total knee arthroplasty using posterior cruciate substituting design implants. Patella is not resurfaced, and circumferential denervation of patella was done. At the end of procedure tourniquet is removed hemostasis is achieved and wound closed in layers over the drain.

All patients are mobilized from post-op day 1. Drain was removed on 2nd post-op day following which intensive physiotherapy under supervision was given to all patients. Unilateral operated patients are discharged after 1-week, bilateral patients are discharged after 2 weeks. Patients were evaluated clinically and radiologically at an interval of 1month, 3 months, 6 months and 1 year, in Orthopaedic OPD.

\section{Oxford knee score- activities and participation questionnaire (OKS-APQ)}

The OKS-APQ represents an optional additional scale (measuring higher level activity/participation), designed to be used in conjunction with the OKS. Initially it is scored in the same way as the OKS i.e. Score each question (item) from 0 to 4 with 0 being the worst outcome and 4 being the best outcome. However, to produce the overall score for the OKS-APQ the resulting summed score, [with possible range from 0 (worst), to 32 (best possible score)], is then converted to a 0 to 100 score. This is simply achieved by taking the resulting summed score (within range 0 to 32), dividing by 32 and then multiplying by 100, as in:

$$
\text { Resulting summed score } \div 32 \times 100
$$

$\mathrm{OKS}=\mathrm{X}(0=$ worst possible score, $48=$ best possible score $)$ 
[if subscales are used:

OKS functional component score $=X(0=$ worst possible score, $100=$ best possible score)

OKS pain component' score $=\mathrm{X}(0=$ worst possible score, $100=$ best possible score)]

OKS-APQ=Y $(0=$ worst possible score, $100=$ best possible score)

The OKS is a 12-item questionnaire on activities of daily living. The OKS has been developed and validated specifically to assess function and pain after TKR. Out of 12 items, 5 for assessing pain and 7 for assessing function. Each item is worth equal weighting (1 to 5) for a total possible score ranging from 12 to 60 . A higher score indicates a better outcome.

The outcome categories based on oxford knee scoring system: excellent (40-48), good (30-39), fair (20-29) and poor (0-19).

\section{RESULTS}

Study done in 39 patients who underwent total knee arthroplasty using posterior cruciate substituting design.

Table 1: Oxford knee score.

\begin{tabular}{|ll|}
\hline Outcome & \multicolumn{1}{c|}{ Score } \\
\hline Excellent & $40-48$ \\
\hline Good & $30-39$ \\
\hline Fair & $20-29$ \\
\hline Poor & $0-19$ \\
\hline
\end{tabular}

Table 2: Demographic details in the study.

\begin{tabular}{|lll|}
\hline Age interval & $\begin{array}{l}\text { Number of } \\
\text { cases }\end{array}$ & Percentages \\
\hline $\mathbf{5 0 - 5 5}$ & 3 & 7.6 \\
\hline $\mathbf{5 6 - 6 0}$ & 6 & 15.4 \\
\hline $\mathbf{6 1 - 6 5}$ & 19 & 48.7 \\
\hline $\mathbf{6 6 - 7 0}$ & 11 & 28.2 \\
\hline Gender & & \\
\hline Male & 25 & 64 \\
\hline Females & 14 & 36 \\
\hline Side of injury & & \\
\hline Right & 21 & 54 \\
\hline Left & 18 & 46 \\
\hline Cause of injury & & \\
\hline $\begin{array}{l}\text { Primary } \\
\text { Osteoarthritis }\end{array}$ & 36 & 92 \\
\hline $\begin{array}{l}\text { Traumatic } \\
\text { Osteoarthritis }\end{array}$ & 3 & 8 \\
\hline
\end{tabular}

The majority of the patients were from age group of 61-65 years. The youngest patient was 52 years of age and oldest was 68 years. There was a male predominance in the ratio of 3:2 in our study. There was a predominance of right side.

Out of 39 patients, 36 was diagnosed as primary osteoarthritis and 3 were post traumatic osteoarthritis.

Table 3: The Oxford knee score outcome in study.

\begin{tabular}{|lll|}
\hline Score & $\begin{array}{l}\text { Number of } \\
\text { cases }\end{array}$ & Percentages \\
\hline Excellent & 28 & 71.8 \\
\hline Good & 6 & 15.3 \\
\hline Fair & 3 & 7.7 \\
\hline Poor & 2 & 5.2 \\
\hline
\end{tabular}

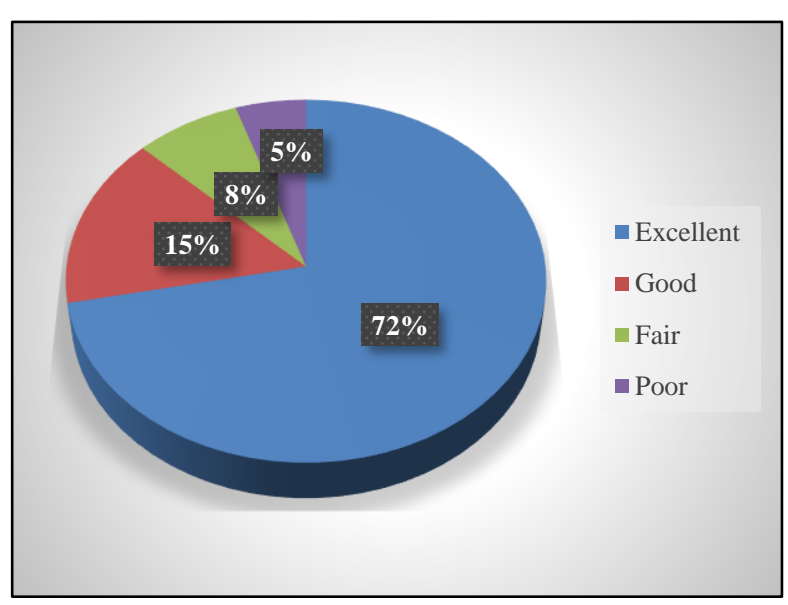

Figure 1: Oxford knee score outcome.

Most of the patients in study have excellent outcome $71.8 \%$ followed by good results of $15.3 \%$ after treatment.

Out of 39 patients and 4 patient had post op suprapatellar fullness, which was relieved with medications for 3 weeks and 2 patients ( 2 knees) without no signs of immediate post-operative period, developed infection after 6 months followed which underwent staged revision total knee replacement.

\section{DISCUSSION}

Total knee arthroplasty is generally an effective procedure and is associated with substantial functional improvement. Elderly patients who were having difficulty in daily activities because of degenerative arthritis found good relief after total knee arthroplasty. There was a substantial relief of joint pain, increased mobility, correction of deformity and an improvement in the quality of life of the patients following posterior cruciate sacrificing total knee arthroplasty. With the varied amount of implant designs available the posterior cruciate substituting design was found to be effective.

Swanik et al found that following total knee arthroplasty, patients were able to reproduce joint position and improve 
mobility significantly. ${ }^{5}$ These changes may result from the retensioned capsulo-ligamentous structures and reduced pain and inflammation. The balance index also improved significantly from the preoperative to the postoperative evaluation. The group treated with the posterior stabilized prosthesis more accurately reproduced joint position when the knee was extended from a flexed position. Retention of the posterior cruciate ligament does not appear to significantly improve proprioception and balance compared with those functions in patients with a posterior stabilized total knee design.

Gait analysis by Andriacchi et al and others found that individuals with PCL retaining prostheses have a more symmetrical gait, especially during stair climbing, than do individuals with either PCL-sacrificing/ PCL-substituting designs. ${ }^{6}$ They showed decreased knee flexion during stair climbing and a tendency to lean forward in a quadricepssparing posture in patients with PCL-sacrificing/ PCLsubstituting designs. They postulated that these observations may indicate inadequate rollback of these designs or possibly the loss of a proprioceptive role of the PCL. These observations have been cited as reasons to retain the PCL. Gait analysis in studies contradicts the conclusions of these earlier studies, however, after comparing PCL-substituting/sacrificing knees with normal controls. ${ }^{8}$ These earlier observations are refuted further by in vivo studies by Stiehl et al, Victor et al who used fluoroscopy during single-stance deep knee bends to show a paradoxical forward translation of the femorotibial contact point during weight bearing flexion in some PCLretaining, PCL-substituting/sacrificing knees studies showed more uniform femoral rollback. ${ }^{8,9}$

A randomized trial by Maruyama et al comparing patients with bilateral TKR, identified a greater range of movement with PCL substituting/sacrificing as compared with PCL retaining TKR. ${ }^{10} \mathrm{~A}$ recent metaanalysis concluded that there was an improvement in flexion of $8^{\circ}$ in PCLsubstituted designs compared with PCL-retention. ${ }^{11}$ However, any improvement in flexion seemed limited and not associated with improved function. Other investigators have not detected improved flexion with PCLsubstitution/sacrificing. The PCL may not function even when a PCL-retaining design is used.

Barrack et al found that total knee arthroplasty with retention of the patella yielded clinical results that were comparable with those after total knee arthroplasty with patellar resurfacing. ${ }^{11}$ Barrack et al concluded that postoperative anterior knee pain is related either to the Component design or to the details of the surgical technique, such as component rotation, rather than to whether or not the patella is resurfaced. Nutton et al concluded that knee function was not improved by patella resurfacing when compared to a matched group of patients without resurfacing. ${ }^{12}$ Wood et al concluded that total knee arthroplasty with patellar resurfacing exhibited inferior clinical results as compared to total knee arthroplasty with patellar retention. ${ }^{13}$
Total knee arthroplasty with patellar resurfacing exhibited significant limitation of knee extension, which was significantly associated with the presence of post-surgery anterior knee pain. ${ }^{13}$ Patellar resurfacing does not guarantee a painless patellofemoral joint. In our study, all patella's were not resurfaced. All patella's were circumferentially denervated. There was no anterior knee pain in any of our subjects. ${ }^{14}$

\section{CONCLUSION}

Total knee arthroplasty improves the functional ability of the patients. Post operatively, patients had pain free joint movements with correction of deformity. In patients with advanced osteoarthritis, gross varus deformity, fixed flexion deformity posterior cruciate ligament sacrificing total knee replacement will give greater mobility and function. In patients with osteoarthritis and fixed flexion deformity total knee arthroplasty is preferred mode of management.

\section{Funding: No funding sources \\ Conflict of interest: None declared}

Ethical approval: The study was approved by the institutional ethics committee

\section{REFERENCES}

1. Yacovelli S, Grau LC, Hozack WJ, Courtney PM. Functional Outcomes are Comparable Between Posterior Stabilized and Cruciate-Substituting Total Knee Arthroplasty Designs at Short-Term Followup. J Arthroplasty. 2021;36(3):986-90.

2. shii Y, Noguchi H, Sato J, Sakurai T, Toyabe SI. Anteroposterior translation and range of motion after total knee arthroplasty using posterior cruciate ligament-retaining versus posterior cruciate ligament-substituting prostheses. Knee Surg Sports Traumatol Arthrosc. 2017;25(11):3536-42.

3. Saini C L, Gautam V K, Mehta V M. Comparision of outcomes of posterior cruciate ligament substituting vs retaining in total knee arthroplasty-a prospective, randomised, open labelled study of 30 cases. Indian J Orthop Surg. 2020;6(4):277-82

4. Miller A, Friedman B. Fascial arthroplasty of the knee. J Bone Joint Surg Am. 1952;34(1):55-63.

5. Swanik BC. Proprioception, kinesthesia, and balance after total knee arthroplasty with cruciate retaining and posterior stabilized prostheses. J Bone Joint Surg. 2004;86:328-34.

6. Andriacchi TP, Galante JO, Fermier RW. The influence of total knee Replacement design on walking and stair climbing. J Bone Joint Surg. 1982;64:1328.

7. Dennis DA, Clayton ML, O'Donnell S. Posterior cruciate condylar total knee arthroplasty: average 11year followup examination. Clin Orthop Relat Res. 1992;281:168.

8. Dennis DA, Komistek RD, Stiehl JB. Range of motion after total knee arthroplasty: the effect of 
implant design and weight-bearing conditions. J Arthroplasty. 1998;13:748.

9. Maruyama S, Yoshiya S, Matsui N, Kuroda R, Kurosaka M. Functional comparison of posterior cruciate retaining versus posterior stabilized total knee arthroplasty. J Arthroplasty. 2004;19:349-53.

10. Kim RH, Scott WN. Operative techniques: total knee replacement. Philadelphia: Saunders-Elsevier. 2009;91-103.

11. Barrack L. Resurfacing of the patella in total knee arthroplasty: a prospective, randomized, doubleblind study. J Bone Joint Surg. 1997;79:1121-31.

12. Myles CM, Rowe PJ, Nutton RW, Burnett R. The effect of patella resurfacing in total knee arthroplasty on functional range of movement measured by flexible electrogoniometry: 2006;21(7):733-9.
13. Wood. Clinical outcomes and walking analysis after total knee arthroplasty with and without patellar resurfacing: a prospective randomized trial. J Bone Joint Surg. 2005;338-39.

14. Jacobs WCH, Clement D, Wymenga AB. Retention versus removal of the posterior cruciate ligament in total knee replacement. A systematic literature review within the Cochrane framework. Acta Orthopaedica. 2005;76:757-68.

Cite this article as: Reddy KVB, Chary NB, Sumanth B. A study on functional outcome of posterior cruciate ligament substituted total knee arthroplasty. Int J Res Orthop 2021;7:1161-5. 